\title{
Prospective directions of state support of the national innovation system of Russia
}

\author{
Dmitry Serpuhovitin* \\ Institute of Public Administration and Civil Service RANEPA, Moscow, Russia
}

\begin{abstract}
The article presents an original methodology for selecting the most popular measures of state support of the national innovation system of a country with usage of numerical methods of clustering. The clustering methodology is based on a combination of indexes: Global Innovation Index, Gross Natural Income and Human Development Index. In the lists of countries and their corresponding clusters obtained as a result of empirical analysis, the most demanded measures of state support of the national innovation system were identified on the base of retrospective dynamics of Global Innovation Index indicators characterizing the state support of the national innovation system. For the obtained indicators of the Global Innovation Index, recommendations were given for the direction of development of the national innovation system of Russia. Classical clustering methods were used as analysis instruments: Density-based spatial clustering of applications with noise and K-Means, The Silhouette Coefficient implemented in the sklearn library of Python programming language was used as a quality metric.
\end{abstract}

\section{Introduction}

The national innovation system (NIS) develops under the influence of national policy in the context of the action of specific state-formal and non-formal institutions of management [1], formed as a result of the historical path of each particular state. It is quite normal that the structure of the NIS is unique for each country, however, there are tools for assessing the effectiveness of the NIS. One of these tools is the Global Innovation Index [2] (Global Innovation Index - GII), compiled by Cornell University, INSEAD and the World Intellectual Property Organization.

The index is formed on both subjective and objective data obtained from sources such as the International Telecommunication Union, the World Bank and the World Economic Forum, etc. The index was introduced in 2007 by the French business school INSEAD and the British magazine World Business. The GII is commonly used by corporate executives and governments to compare countries in terms of their level of innovation activity [3].

The GII index is calculated by averaging of the scores of indicators in two sub-indexes: characterizing the "Input conditions" conditions for innovation activity - "Potential of innovation" and "Output results" - "Results of innovation activity". Sub-indexes consist of 5

${ }^{*}$ Corresponding author: d.serpuhovitin@gmail.com 
and 2 groups of indicators, also combined from 2 to 5 elements - statistical and calculated data. The structure of the index indicators is shown in Fig.1.

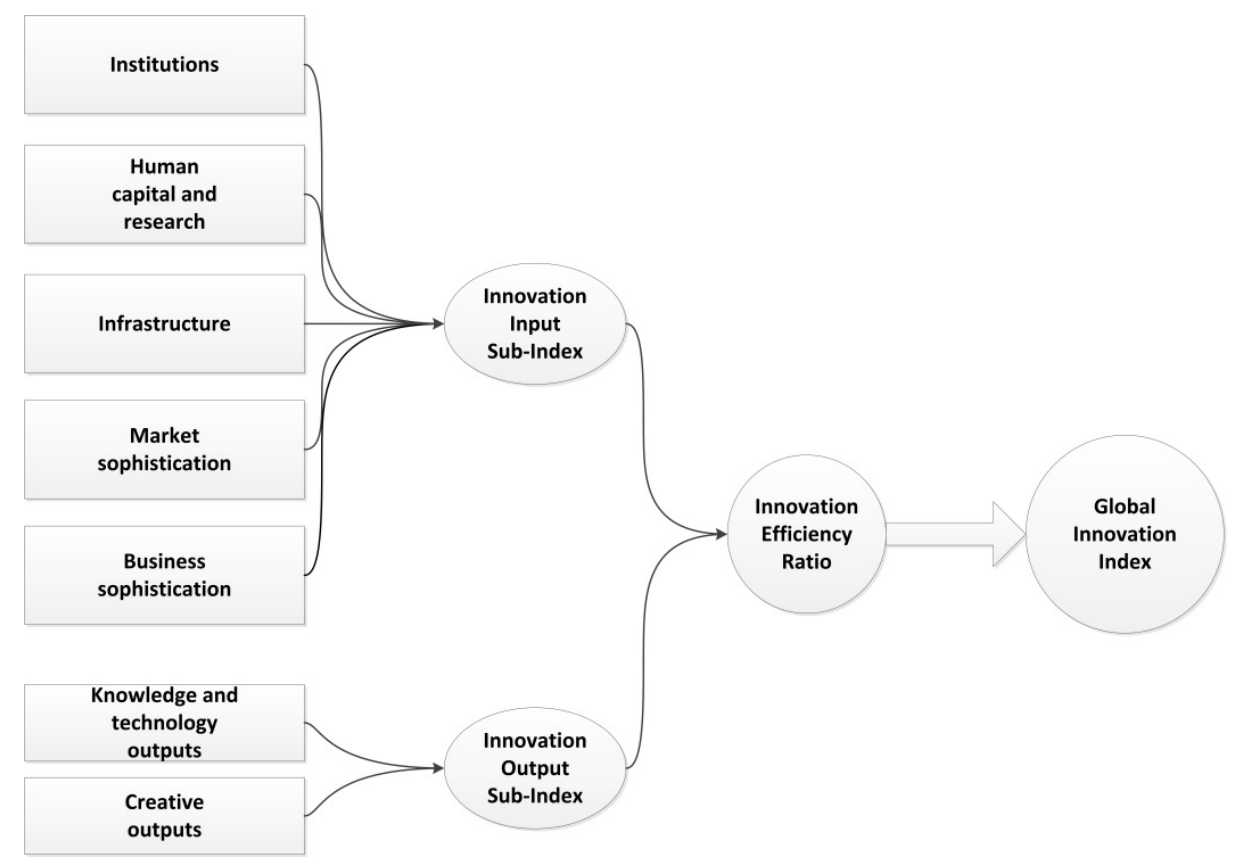

Fig. 1. Global Innovation Index structure.

A detailed description of the components of the index, as well as the GII calculation methodology, the authors of the index provide in the appendices to the annually published report containing the GII index (usually, in Appendix 1 "The Global Innovation Index Conceptual Framework"). A world ranking of countries, which is formed annually, on the value of the index, characterizes the level of their innovative activity.

\section{Problem statement and data description}

The growth of the country's gross domestic product directly depends on the level of development of its NIS. Such researchers as Borisova E.Yu. [4], Nikonova Ya. I. [5], Kacprzyk A. [6] and others note a direct connection between such characteristics of the country's economy as the value of Gross National Income (GNI), the level of competitiveness and economic security or the ability to develop sustainably with the state of its innovation system. The NIS is formed in the conditions of state institutions of management, in many countries programs have been developed to support the NIS to achieve the established national goals.

In the Russia, since 2011, program documents have been developed and implemented at all Government levels to support and develop the NIS and its elements. [7] Despite this, the score of Russia in the world innovation rating has a downward trend since 2015 (see Fig. 2.) 


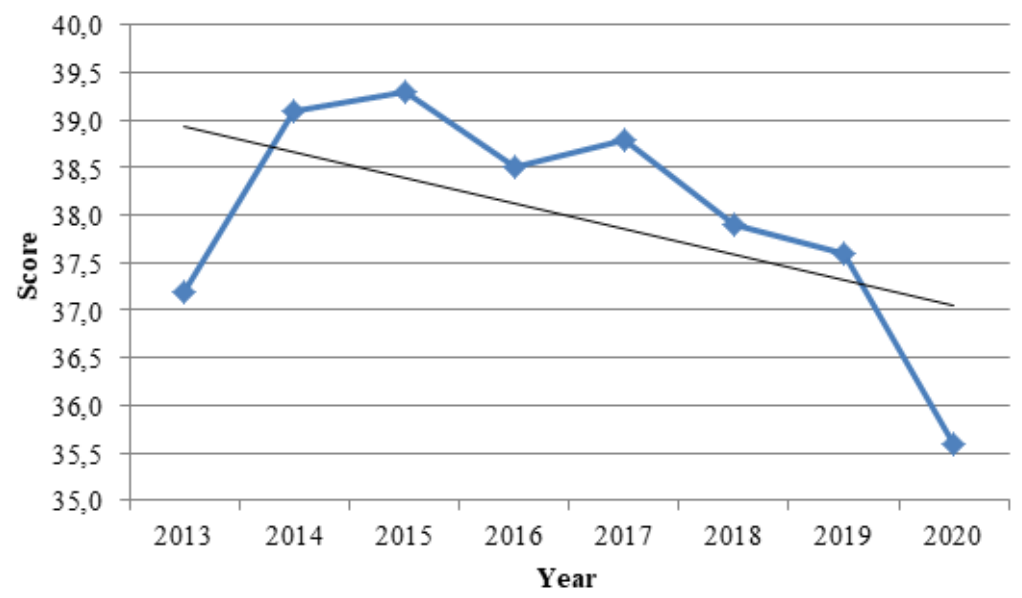

Fig. 2. Russia score, according to the GII.

Note:

1. Formed by Author on the Global Innovation Index reports.

2. GII 2020 Index was not used in calculations.

The dynamics of the GII score cannot be explained only by external political and economic reasons (for example, the imposition of sanctions, currency fluctuations, etc.) or structural changes in the Russian economy [8]. In our opinion, the current state support programs for NIS, aimed at developing its specific areas, as they are implemented, open up potential in other, related areas.

In other words, the specifics of state support for NIS in Russia lead to a disproportional increase in its elements and, as a consequence, to a general decrease in score. We believe that adjusting the directions of state support for NIS Russia may lead to stabilization of Russia's place in the rating or even its growth.

The state of government support can be assessed through a set of components of the GII index and the resulting economic effect - GNI. Based on this, the main hypothesis was formulated: it is possible to identify such components of the GII index that characterize state support for NIS, the change in which significantly affects the country's rank in the GII rating, as well as GNI.

For the purposes of this study, 2 groups of indicators were selected from the components of the GII index (for 2013-2019), characterizing the state support of the NIS: Integral indicators for 2013-2019, included in the 1st group of sub-indexes (5 indicators): Political environment, Regulatory environment, Business environment, Credit, Innovation linkages.

Partial indicators - 37 indicators (group 2) for 2013-2019, are shown in Table 1.

Table 1. List of 37 indicators.

\begin{tabular}{|c|l|}
\hline № & \multicolumn{1}{|c|}{ Indicator } \\
\hline 1 & Political stability and absence of violence/terrorism \\
\hline 2 & Government effectiveness \\
\hline 3 & Press freedom \\
\hline 4 & Regulatory quality
\end{tabular}


Continuation of table 1.

\begin{tabular}{|c|c|}
\hline 5 & Rule of law \\
\hline 6 & Cost of redundancy dismissal \\
\hline 7 & Ease of starting a business \\
\hline 8 & Ease of resolving insolvency \\
\hline 9 & Ease of paying taxes \\
\hline 10 & Expenditure on education \\
\hline 11 & Government expenditure on education per pupil, secondary \\
\hline 12 & Pupil-teacher ratio, secondary \\
\hline 13 & Tertiary enrolment \\
\hline 14 & Graduates in science and engineering \\
\hline 15 & Researchers \\
\hline 16 & Gross expenditure on R\&D - GERD \\
\hline 17 & Government's online service \\
\hline 18 & Electricity output \\
\hline 19 & Logistics performance \\
\hline 20 & Environmental performance \\
\hline 21 & Ease of getting credit \\
\hline 22 & Domestic credit to private sector \\
\hline 23 & Microfinance institutions' gross loan portfolio \\
\hline 24 & Ease of protecting investors \\
\hline 25 & Venture capital deals \\
\hline 26 & Market access for non-agricultural exports \\
\hline 27 & Intensity of local competition \\
\hline 28 & Firms offering formal training \\
\hline 29 & University/industry research collaboration \\
\hline 30 & State of cluster development \\
\hline 31 & GERD financed by abroad \\
\hline 32 & Joint venture/strategic alliance deals \\
\hline 33 & Patent families filed in at least two offices \\
\hline
\end{tabular}


Continuation of table 1.

\begin{tabular}{|l|l|}
\hline 34 & Royalties and license fees payments (\% of service imports) \\
\hline 35 & Foreign direct investment net inflows \\
\hline 36 & Patent cooperation treaty international applications by origin \\
\hline 37 & Foreign direct investment net outflows \\
\hline
\end{tabular}

Additionally, the data set for the study was supplemented with the resulting GII index and data on the GNI (Gross National Income) of the World Bank [9] for the same period (2013-2019) of the corresponding countries of the world.

\subsection{Data Description}

The peculiarity of the database is its heterogeneity: the number of indicators of group 2 and the number of countries varies depending on the year. This is presumably caused by a change in the names of countries, the deletion of some indicators (for example, "Press freedom") by the authors-compilers of the index, as well as the merging of several indicators into one, which was a consequence of a change in the methodology for compiling the GII index (Fig. 3).

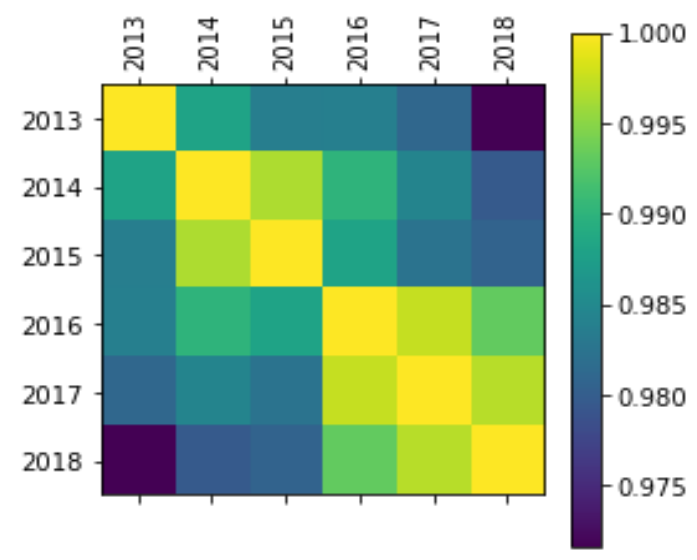

Fig. 3. Index GII correlogram from 2013 till 2019.

Summary statistics of changes in the number of countries and indicators are shown in Table 2 .

Table 2. Changes in the number of the 2 group of countries and indicators GII.

\begin{tabular}{|c|c|c|c|c|c|c|c|}
\hline & 2013 & 2014 & 2015 & 2016 & 2017 & 2018 & 2019 \\
\hline The number of the 2 group indicators & 37 & 37 & 35 & 36 & 36 & 35 & 35 \\
\hline Number of countries & 141 & 142 & 140 & 204 & 126 & 125 & 127 \\
\hline
\end{tabular}

The change by the authors of the index in the number of countries and sub-indexes resulted in gaps in the GII samples in both groups. The gaps, while preparing the data, were 
filled with the average value of the indicator for previous years. The final dataset includes from 125 to 204 countries, depending on the year, see Fig.4.

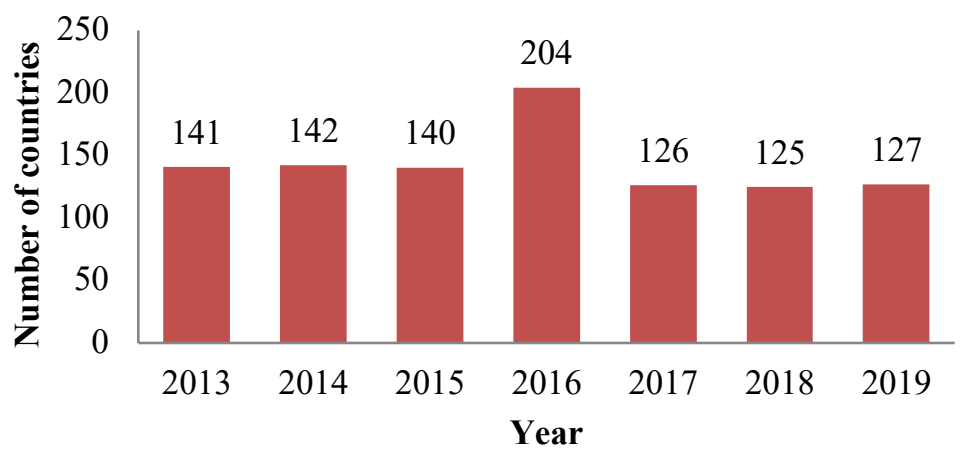

Fig. 4. Number of countries in the basical GNI.

As a supplement, the GNI indicator provided by the World Bank for 2013-2019 was selected in current US dollars. The number of countries also varied (Fig. 5).

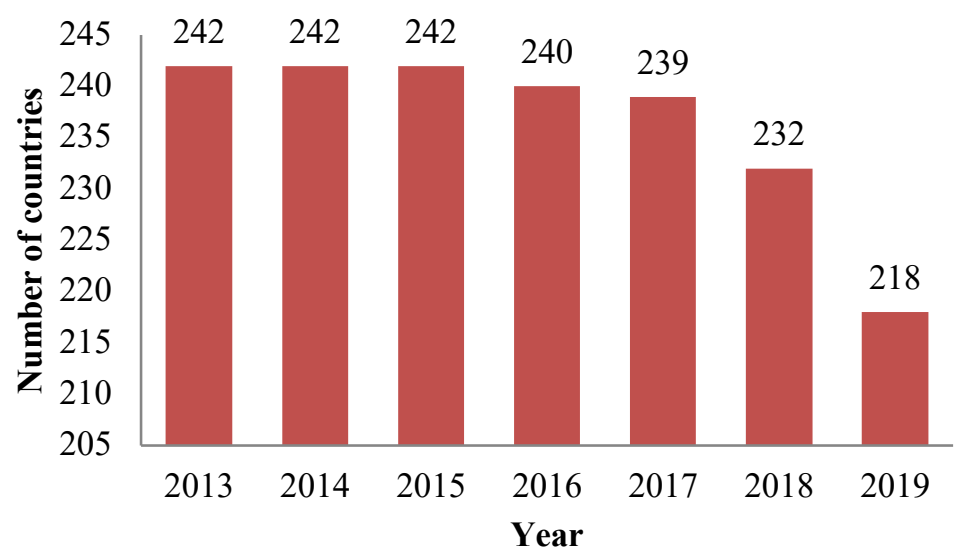

Fig. 5. The number of countries in the GNI.

After preprocessing the data, the number of countries was 180 in each year, the number of omissions was reduced to zero.

The calculations were carried out in the Jupiter notebook v.6.0.3 environment in the Python v.3.7.7 programming language using the libraries:

- Pandas v.1.0.5 - operations with data tables;

- Numpy v.1.19.1 - mathematical operations on arrays;

- Scipy v.1.5.0 - statistical analysis;

- Sklearn v.0.23.1 - statistical analysis.

\subsection{Methodology}

Countries are at different levels of socio-economic development, have their own system of formal and informal institutions; goals and priorities for the development of the national economy; own scientific production and technological base, etc. - all this influences the 
methods and instruments of state support of the NIS. In addition, the action of external and internal factors, such as, for example, global financial and economic crises, sanctions, local conflicts or emergencies, lead to changes in GNI and adjustments to NIS development programs, which can change the components of the GII index. Based on this, it is obvious that the search for the most influential indicators should be carried out within a group of countries that are similar in the period under consideration.

There are many ways to classify countries: geographic, national, economic, or when their NIS was created. However, for the purposes of this study, it is advisable to group countries based on the values of the available indicators in a particular year.

To identify indicators that have the greatest impact on improving the rating of countries, the following methodology is proposed. As a first step, countries are divided into groups (clusters) with similar values of the studied indicators. Further, the countries are highlighted that during the study period improved their positions, moving from a lower to a higher cluster. Further, it is proposed to compare the values of the indicators for the countries that left the cluster with the indicators of the countries that remained in the cluster and highlight the differing indicators. We assume that the transition from cluster to cluster occurred due to differing indicators, that is, these differing indicators are the most influential indicators that determine the country's place in the ranking. To select the most influential indicators from the differing indicators by the Pareto method, it is proposed to select indicators, the sum of the values of which in the module was $80 \%$ of the sum of all indicators in the country. After that, the obtained indicators are proposed to be aggregated for all countries and clusters and to highlight the most common ones.

We propose to use one- and two-factor clustering: first, we will group countries only by the values of the GII indicators, and then we will take into account the values of the GII and GNI indicators together. When carrying out both one- and two-factor clustering, the condition of coincidence of more than $51 \%$ of indicators was taken as a criterion.

\subsection{Research Progress Statement}

\section{Step 1. One-factor clustering.}

Countries can be divided into groups (clusters) according to the GII index and the GNI level, regardless of the year, while the number of clusters must coincide, and their number must coincide with the number of UN groups. Thus, within the clusters there will be similar countries in terms of the level of development of the NIS.

The conducted clustering showed that the countries were indeed distributed across clusters evenly in each year from 2013 to 2019, and the number of clusters coincided with the UN classification. This was verified by the KMeans method of the sklearn library. The clustering results are shown in Fig. 6 and Fig. 7 for GII and GNI levels, respectively. As can be seen from the diagram (Fig. 6), countries in terms of gross domestic product are distributed evenly from 2013 to 2015 across clusters, that is, the standard deviation is much less than the minimum number of countries in a cluster.

From 2016 to 2019 the distribution of countries by clusters ceases to be uniform, while the number of countries in cluster 0 prevails. This may be due to the consequences of the world financial crisis of 2014-2015 and the results of measures taken by the government to support and restore economies. 


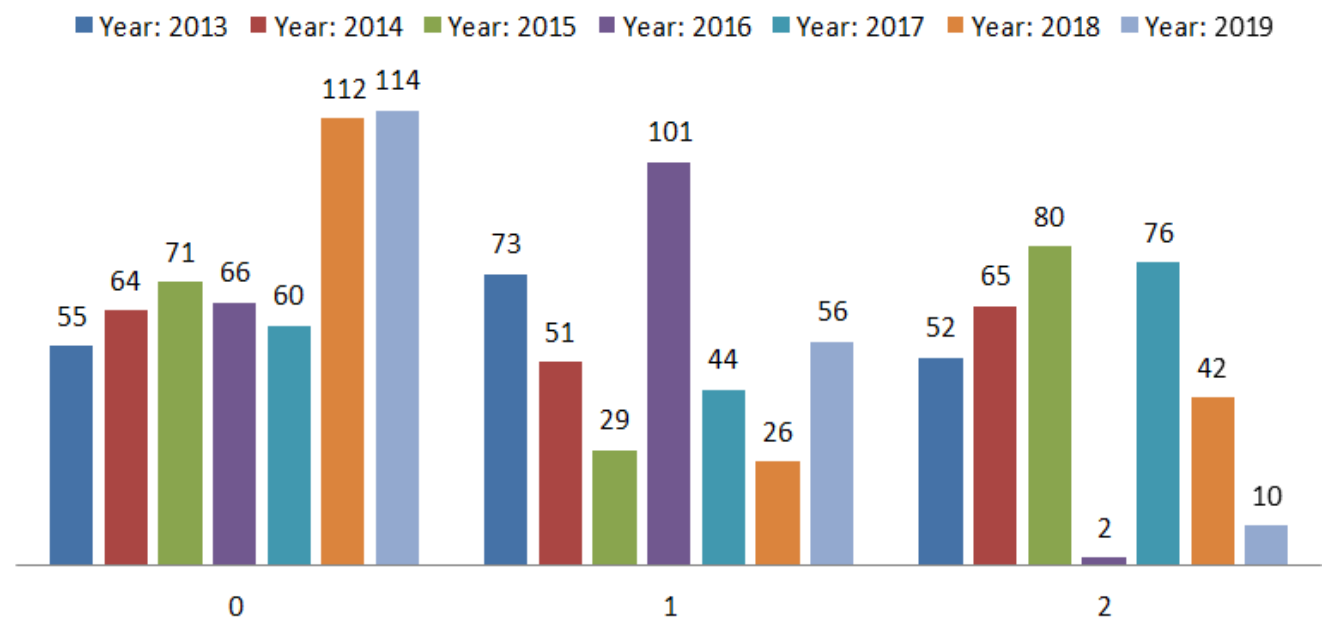

Fig. 6. Country clustering to the GNI in 2013-2019.

The clustering of countries according to the GII index is more even (Fig. 7), with the exception of 2017, which is dominated by cluster 0 , but the standard deviation is close to the minimum number of countries (cluster 2, the number of countries is 20) and is 24.8.

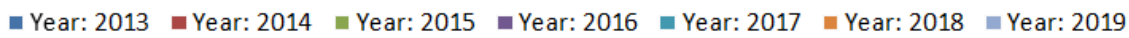

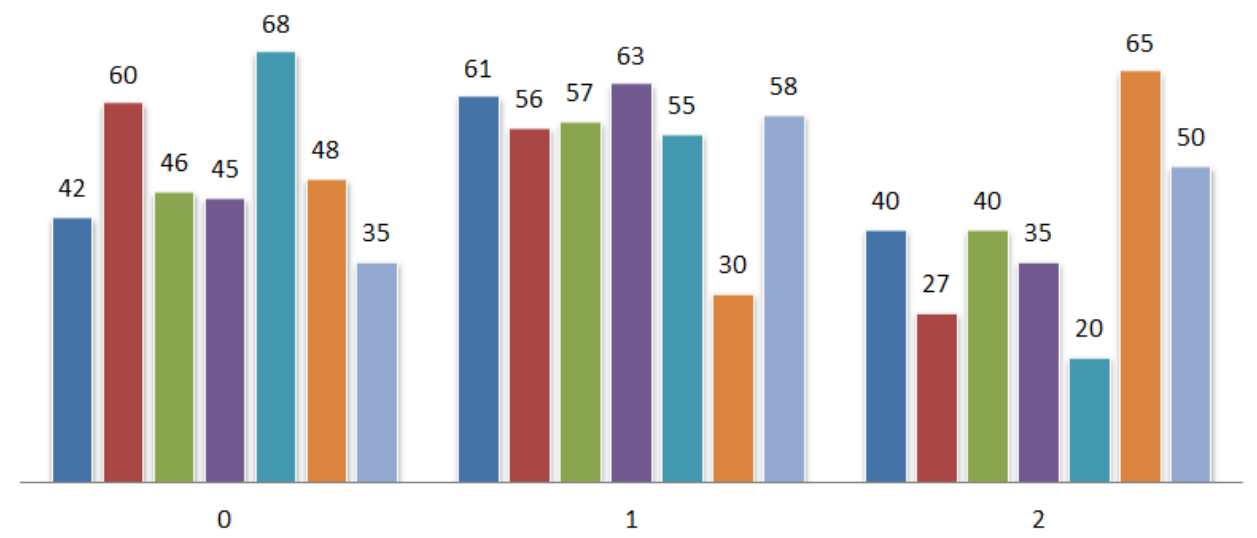

Fig. 7. Country clustering to the GNI in GII in 2013-2019.

Since there is a deviation in only one year, it can be assumed that, as a whole, across the samples, the countries are distributed evenly.

Further, the data were reduced to one dimension by the "StandardScaler()" method of the sklearn library, and the Mann - Whitney U-test method was used to check the relationship of the studied dataset with the GII and GNI indices (belonging of the above datasets to the same general population). The hypothesis is considered confirmed if the threshold p-value $<0.05$. The $\mathrm{p}$-value for each case actually turned out to be significantly less than the threshold value (Fig. 8). 


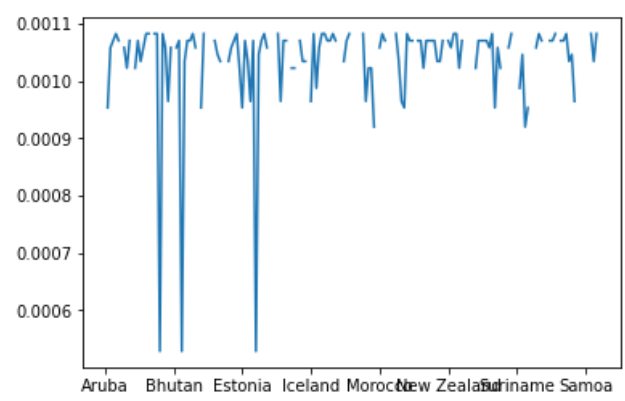

p-value for indexes GII \& GNI

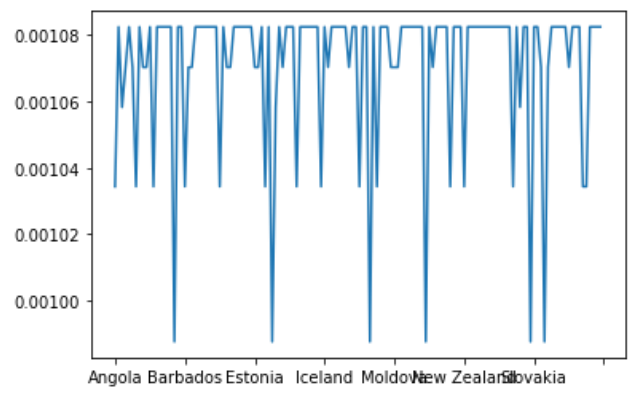

p-value for 5 indicators (first and second group) and GII index

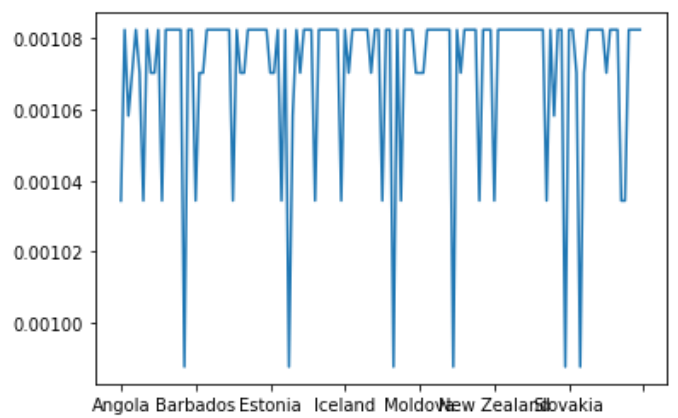

Fig. 8. p-value for the second group of GII.

As can be seen from the graphs for at least 140 countries, the GII and GNI indicators, as well as the analyzed indicator sets, belong to the same general population.

Further:

1) The values of the GII indices and GNI values for each year from 2013 to 2019 are brought to a single scale.

2) The range of the optimal number of clusters for the GII (Fig. 9) and GNI (Fig. 10) samples was found by years from 2013 to 2019 using the "Silhouette()" method (sklearn libraries).
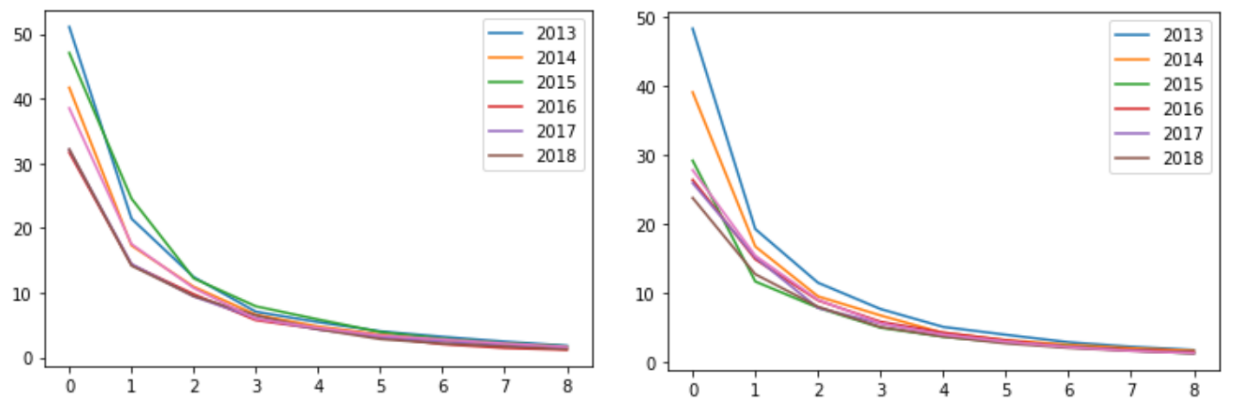

Fig. 9. Determining the number of GII clusters. Fig. 10. Determining the number of GNI clusters. 
3) The optimal number of clusters was selected for the GII and GNI samples.

As can be seen from the graphs (Figs. 9 and 10), the optimal number of clusters is in the range of $3-4$. Validation by the mean shift method showed that the number of clusters for both GII and GNI varies from year to year. As a result, the arithmetic mean number of clusters for the years 2013-2019 for GNI and GII was chosen equal to 3 .

4) Clustering of countries by the GII was carried out.

\section{Step 2. Two-factor clustering}

Countries can be divided into a finite number of groups (clusters) by the GII and GNI value together, regardless of the year. Thus, within the clusters there will be countries with a similar level of development of both NIS and GNI, which indicates that they are implementing similar government support.

The change in GNI undoubtedly affects the change in the cluster country, however, since there is an unambiguous relationship between GII and GNI and there is a relationship between indicators of groups 1 and 2 with GII, there is also their relationship with GNI. Onefactor classification may not fully reflect the position of the country in comparison with other countries, that is, its cluster. The GII index characterizes only the country's innovation policy, but not the performance of its economy and may be too narrow an indicator based, in addition, on a part of the subjective assessments of experts. In addition, the NIS is being built and developed individually for each of the countries, respectively, and the measures of state support are also individual. To assess the impact of government support measures for NIS on GNI, it is necessary to carry out a two-factor clustering according to GII and GNI, which will reflect not only individual differences of NIS across countries, but also its effectiveness.

Two-factor clustering was carried out in the following stages:

1) Reducing the data to the same scale. For this, the GNI values were logarithmized.

2) Using the DBScan() method, we searched for the optimal number of clusters.

3) Clustering of pre-processed by the K-means() method according to the number of clusters determined by the DBScan() method according to the GII and the GNI level.

The DBScan() method revealed a large scatter in the number of clusters, which depends on the value of the initial parameters for a particular data set, in particular, on the min samples parameter. The spread ranged from 22 in 2015 to 2 in 2014 (examples in Fig. 11). To compensate for this spread, the number of clusters was averaged over the years and over the combination of the method parameters, and amounted to 10 .

2013

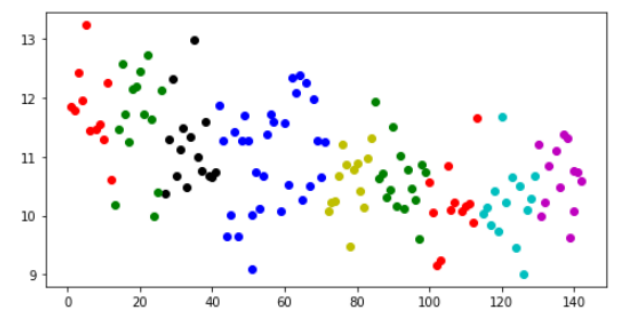

\section{9}

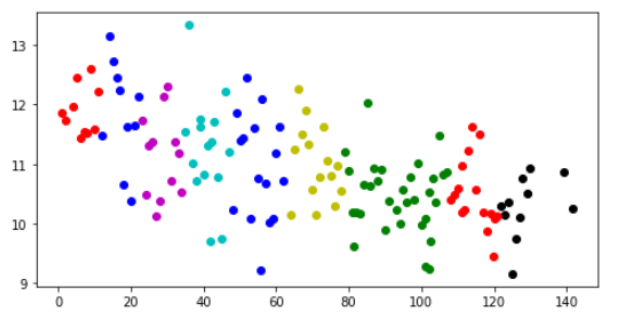

Fig. 11. Two-factor country clustering example 2013 and 2019.

It should be noted that the effect of state support for NIS is stretched over time, while world economic crises, sanctions and changes in the global market can directly affect the 
country's economy. The impact of the combination of the above factors can lead to the change of the cluster by the country.

From the above, it can be seen that, regardless of the type of clustering, countries can be unambiguously divided into groups, while the number of groups is finite, and the distribution of countries in groups is even, all samples are interconnected.

\section{Main findings}

There is a direct and unequivocal relationship between the GII index and the GNI level, which is also indirectly confirmed by the nature of their change. In Fig. 12 and Fig. 13 shows graphs of changes in the GII and GNI index of Russia, respectively.

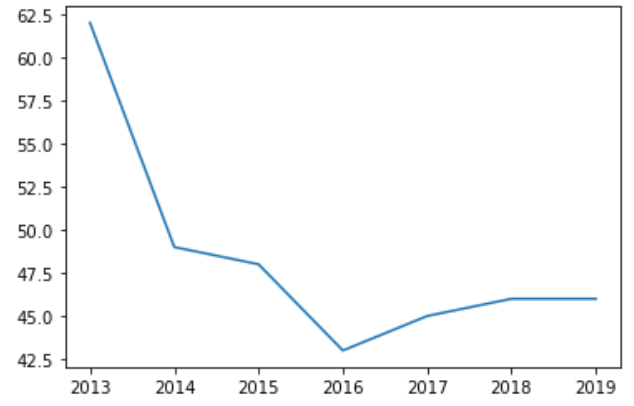

Fig. 12. GII in Russia index change.

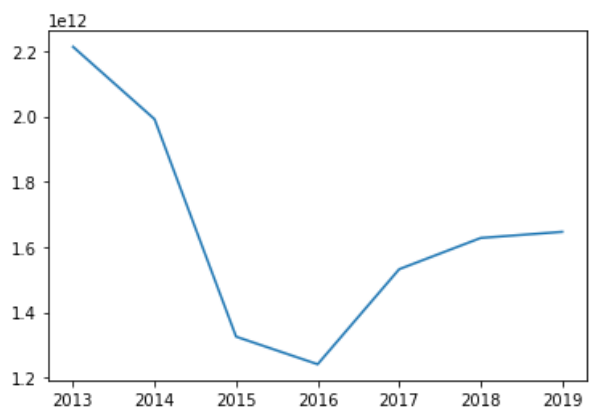

Fig. 13. GNI in Russia index change.

As can be seen from the graphs, the GII index and the GNI level are falling until 2016, and the rate of decline (the slope of the graph) for GNI is lower, which can be explained by the damper effect of methods and instruments of state support, as well as the delayed result of the state's economic policy. The more intensive growth of GDP after 2016 compared to the growth of GII can be associated with the cumulative effect and the delayed effect of previously launched state support programs and the effect of the resonant growth of related sectors of the economy.

The change in the GII index is closely related to the change in indicators characterizing government support and included in the corresponding sub-index. For the Russia, the indicators that have undergone the largest drop (in 2013-2016) are shown in Fig. 15 (the most significant are highlighted in color). Table 6 shows the indicators selected according to the Pareto rule. 


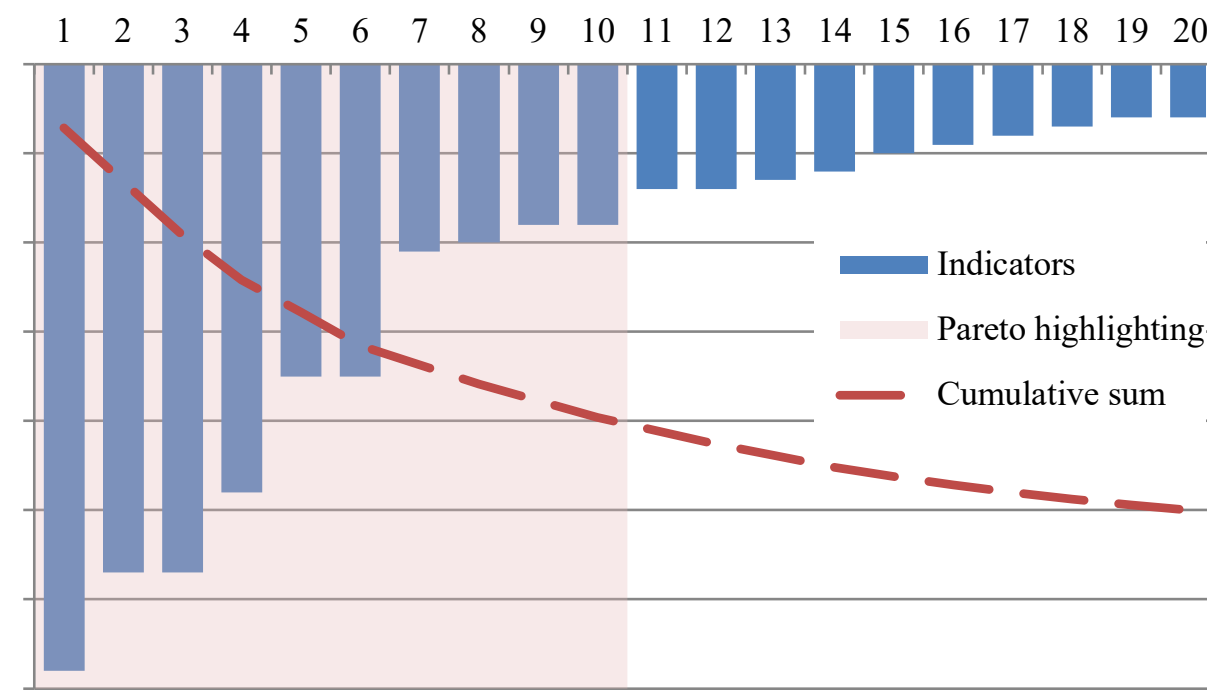

Fig. 14. Chart of the indicators characterizing government support in 2013-2016.

Note: the number of the indicator in the Fig. 14 corresponds to the number of the indicator in table 3.

As can be seen from Fig. 14, in 2013-2016. the largest drop in the values of the following 10 indicators of the Russia included in the GII index was observed, they are listed in Table 3.

Table 3. Indicators of the Russia included in the GII index, which had the largest drop in 2013-2016.

\begin{tabular}{|c|l|}
\hline № & \multicolumn{1}{|c|}{ Indicators } \\
\hline 1 & Environmental performance \\
\hline 2 & Government expenditure on education per pupil, secondary \\
\hline 3 & Ease of getting credit \\
\hline 4 & Logistics performance \\
\hline 5 & Ease of starting a business \\
\hline 6 & Ease of protecting investors \\
\hline 7 & University/industry research collaboration \\
\hline 8 & Foreign direct investment net inflows \\
\hline 9 & Domestic credit to private sector \\
\hline 10 & Foreign direct investment net outflows \\
\hline 11 & Government effectiveness \\
\hline 12 & Ease of resolving insolvency \\
\hline 13 & State of cluster development \\
\hline
\end{tabular}


Continuation of table 3 .

\begin{tabular}{|l|l|}
\hline 14 & Patent families filed in at least two offices \\
\hline 15 & Government's online service \\
\hline 16 & Microfinance institutions' gross loan portfolio \\
\hline 17 & Rule of law \\
\hline 18 & Researchers \\
\hline 19 & Cost of redundancy dismissal \\
\hline 20 & Joint venture/strategic alliance deals \\
\hline
\end{tabular}

From 2016 to 2019, the GII and the GNI level grow and have the same character. During this period, as can be seen from the diagram in Fig. 15, other indicators shown in table 4 show the greatest growth.

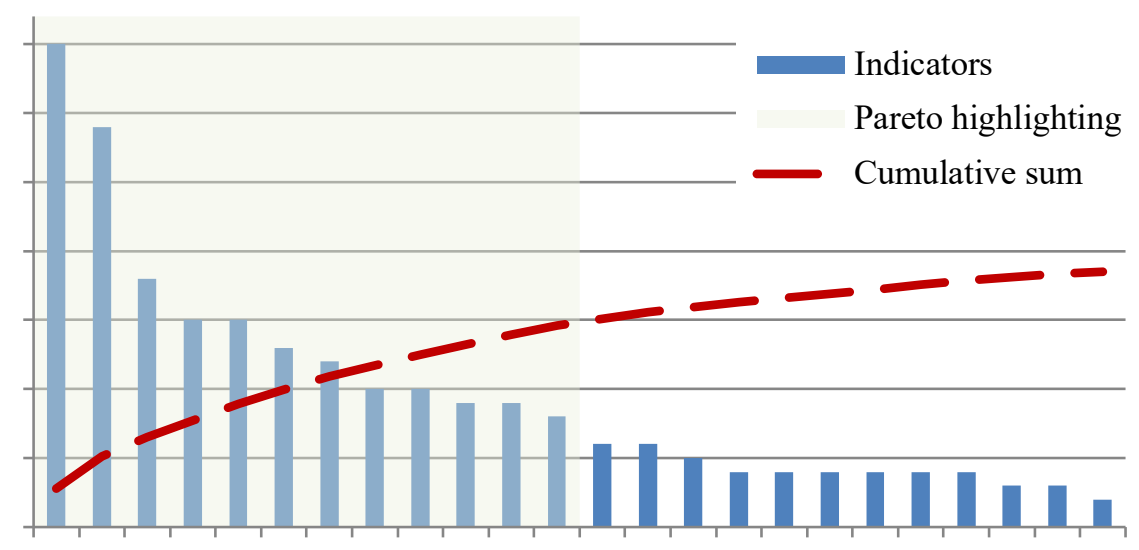

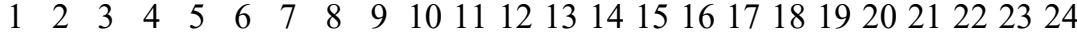

Fig. 15. Diagram of the significance of indicators characterizing the state of NIS support in 2016-2019. Note: the indicator number in the Fig. 15 corresponds to the number of the indicator in table 4.

Table 4. Indicators in the GII index of Russia, showing the most significant positive dynamics in 2016-2019.

\begin{tabular}{|c|l|}
\hline № по п. & \multicolumn{1}{|c|}{ Indicators } \\
\hline 1 & Logistics performance \\
\hline 2 & Venture capital deals \\
\hline 3 & Joint venture/strategic alliance deals \\
\hline 4 & Environmental performance \\
\hline 5 & Microfinance institutions' gross loan portfolio \\
\hline
\end{tabular}


Continuation of table 4.

\begin{tabular}{|c|l|}
\hline 6 & Government effectiveness \\
\hline 7 & Regulatory quality \\
\hline 8 & Government's online service \\
\hline 10 & State of cluster development \\
\hline 11 & Dolitical stability and absence of violence/terrorism \\
\hline 12 & Foreign direct investment net outflows \\
\hline 13 & Rule of law \\
\hline 14 & Cost of redundancy dismissal \\
\hline 15 & Researchers \\
\hline 16 & Ease of starting a business \\
\hline 17 & Expenditure on education \\
\hline 18 & Tertiary enrolment \\
\hline 19 & Ease of protecting investors \\
\hline 20 & GERD financed by abroad \\
\hline 21 & Patent families filed in at least two offices \\
\hline 22 & Gross expenditure on R\&D \\
\hline 23 & Market access for non-agricultural exports \\
\hline 24 & Ease of resolving insolvency \\
\hline & \\
\hline
\end{tabular}

Subtracting the lists of the table. 3 and tab. 4, it is easy to see that in Russia the most significant indicators, a change in which led to a fall or increase in the GII index in 20132019:

1. Environmental performance;

2. Logistics performance;

3. Domestic credit to private sector;

4. Foreign direct investment net outflows.

The strong influence of these indicators on the Russian GII index is easy to explain. So, for example, the second indicator - "Logistics performance" is directly related to the size of the country, the efficiency of the customs service, the development of transport infrastructure, etc., as well as the cost and speed of delivery of goods. The change in the "Domestic credit to private sector" indicator indicates a change in the volume of financial resources provided by financial institutions to private companies in the context of the financial policy pursued by the state.

In 2019, the programs to support the development of these 4 indicators no longer give a tangible increase in the GII index. This may be due to both the exhaustion of their growth potential in the current environment and an increase in the need to support other innovative 
drivers. Referring to the list of the most important indicators obtained by two-factor clustering, we can form the following list of indicators, the development of which can significantly accelerate the growth of the GII index and, consequently, the level of Russia's GNI (see Table 5).

Table 5. Prospective directions of development of NIS Russia.

\begin{tabular}{|c|l|}
\hline № & \multicolumn{1}{|c|}{ Indicators } \\
\hline 1 & Microfinance institutions' gross loan portfolio \\
\hline 2 & GERD financed by abroad \\
\hline 3 & Joint venture/strategic alliance deals \\
\hline 4 & Graduates in science and engineering \\
\hline 5 & Patent families filed in at least two offices \\
\hline 6 & Expenditure on education \\
\hline 7 & Government expenditure on education per pupil, secondary \\
\hline 8 & Royalties and license fees payments (\% of service imports) \\
\hline 9 & State of cluster development \\
\hline 10 & Cost of redundancy dismissal \\
\hline 11 & Ease of paying taxes \\
\hline 12 & Ease of resolving insolvency \\
\hline 13 & Government effectiveness \\
\hline 14 & Gross expenditure on R\&D \\
\hline 15 & Ease of getting credit \\
\hline 16 & Foreign direct investment net outflows \\
\hline 17 & Environmental performance \\
\hline
\end{tabular}

Two-factor analysis of the indicators of the components of the GII rating together with GNI per capita for 140 countries from 2013 to 2019 made it possible to single out for Russia a list of 18 indicators that most strongly affect its annual economic result. To identify the most promising areas of state support, an analysis of the trends of each of the indicators was carried out, which made it possible to combine them into 4 groups:

1) Strong negative dynamics (Fig. 16): 

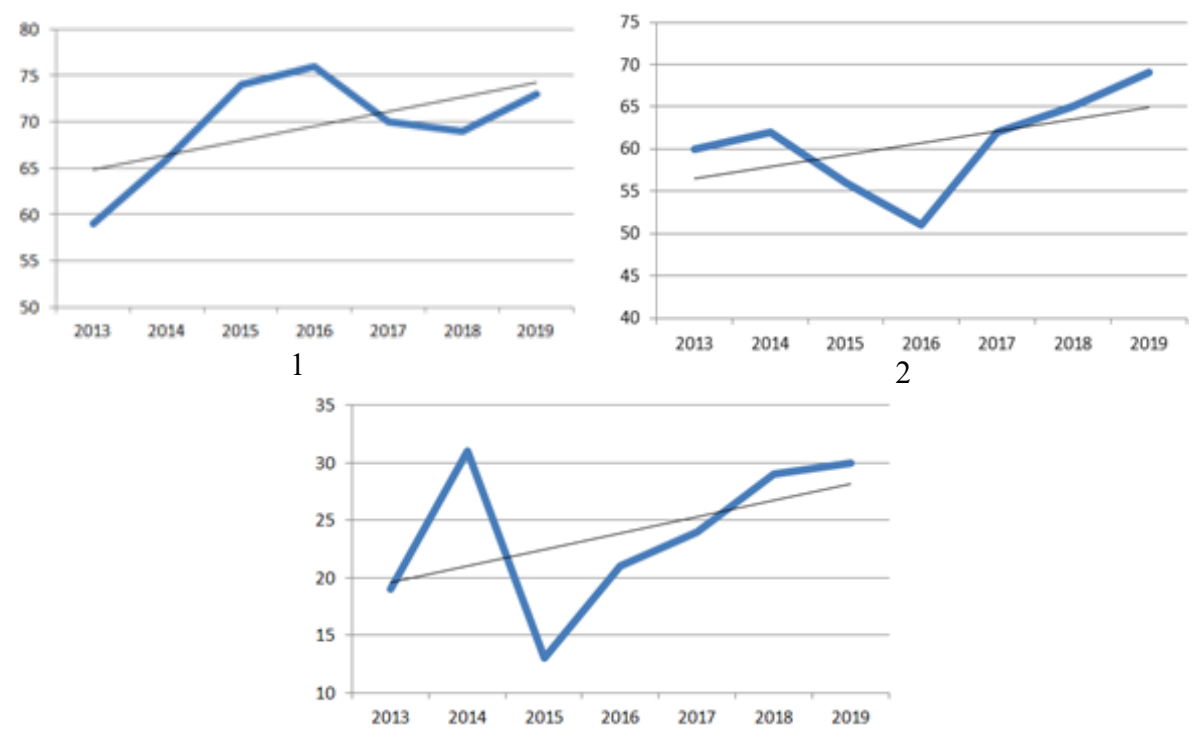

Fig. 16. Strong negative dynamics:

1) GERD financed by abroad;

2) Joint venture/strategic alliance deals;

3) Foreign direct investment net outflows.

2) Weak negative dynamics (Fig. 17):
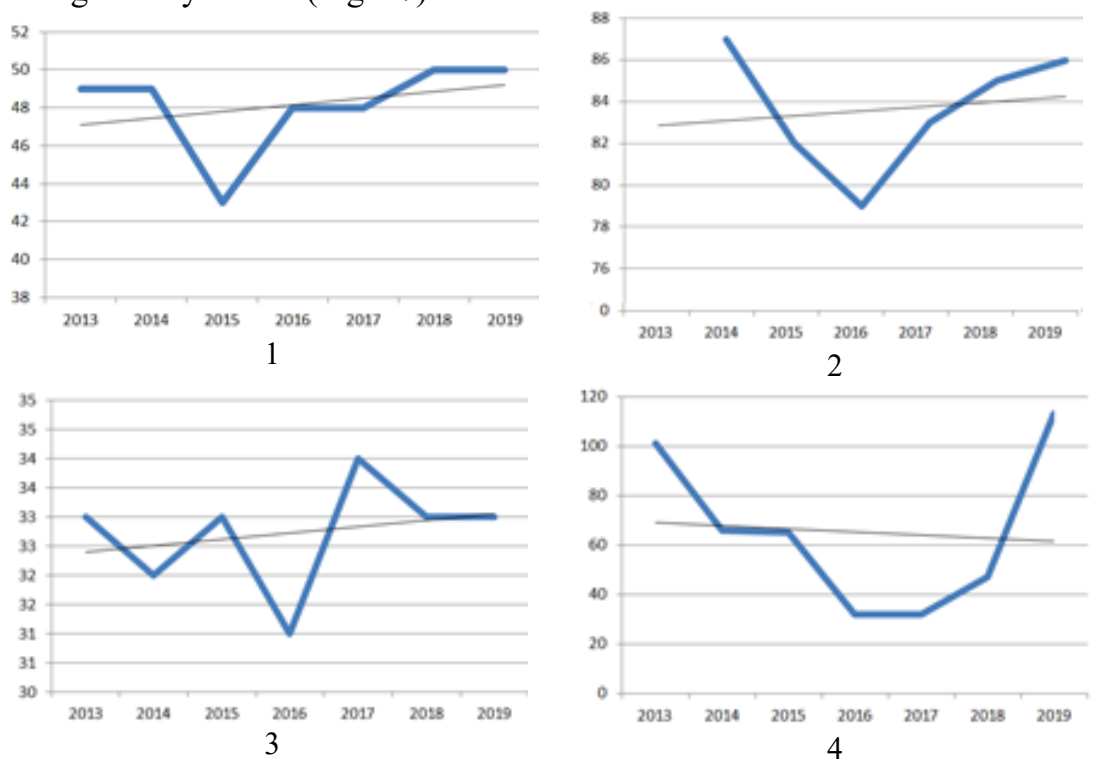

Fig. 17. Weak negative dynamics

1) Ease of resolving insolvency;

2) Expenditure on education;

3) Gross expenditure on R\&D;

Environmental performance.

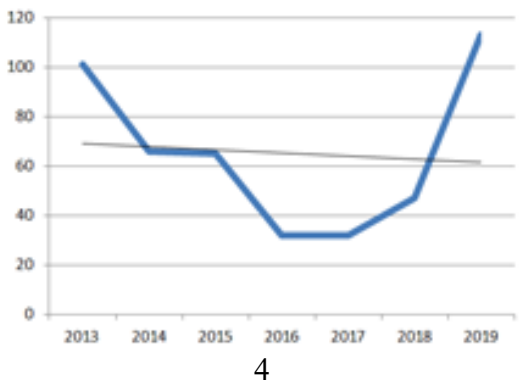


3) Weak positive dynamics:

- Cost of redundancy dismissal;

- Graduates in science and engineering.

4) Strong positive dynamics (the others 9 indicators).

It should be noted that, despite the formally positive trend, the "Environmental performance" indicator has a strongly negative forecast dynamics: as can be seen from the graph, the indicator begins to sharply decrease since 2018, which served as the basis for its inclusion in group 2.

Due to the positive dynamics, as well as the possible growth as a result of the National Projects, the indicators of groups 3 and 4 are not considered, however, monitoring the indicators of group 3 is necessary to prevent their overflow into group 2.

The indicators of the first group are united, first of all, by the susceptibility to the influence of external factors, such as the growing pressure of sanctions and a series of global financial and economic crises. Obviously, direct government support is difficult, nevertheless, stimulating the intensification of interaction with Asian countries hides the growth potential of both the direction and the entire NIS of Russia as a whole.

The indicators of the second group refer to internal factors, which are directly influenced by Federal Target Programs (National Projects), the delayed effect of which has not yet manifested itself. Nevertheless, the accumulated long-term experience of monitoring Federal Target Programs [10] indicates a chronic cash non-execution of programs, which reduces their effectiveness.

In the context of increasing globalization and interpenetration of markets, the influence of external factors is of particular importance in the development of the NIS of Russia. National innovation system agents who do not have sufficient resources to effectively overcome the negative impact of the emerging restrictions, especially in need of government support. In turn, support for the development of international relations by the state will not only increase the rating of NIS Russia in the international index, but will also lead to an increase in its GNI.

\section{Concluding remark}

In the context of increasing globalization and interpenetration of markets, the influence of external factors is of particular importance in the development of the NIS of Russia. National innovation system agents who do not have sufficient resources to effectively overcome the negative impact of the emerging restrictions, especially in need of government support. In turn, support for the development of international relations by the state will not only increase the score of NIS Russia in the international index, but will also lead to an increase in its GNI.

\section{Reference}

1. D. A. Serpukhovitin, Institutional aspects of state management of innovative activity of enterprises, Journal of Economic Theory, 17 (1), 198-212 (2020)

2. Cornell University, INSEAD, and the World Intellectual Property Organization, "Official website of the Global Innovation Index" (2019). Access mode: https://www.globalinnovationindex.org

3. S. A. Balashova, Global indexes as a means of complex assessment of innovative potential, National interests: priorities and security, 6 (2013) 
4. E. Y. Borisova, Evaluation of the impact of innovations on the economic well-being of the country, Applied Econometrics, 18 (2) (2010)

5. Y. I. Nikonova, Research on the relationship between innovation and economic growth of national economies, Scientific and methodological electronic Journal Concept, 15, 2001-2005 (2016)

6. A. Kacprzyk, I. Swieczewska, Is R\&D always growth-enhancing? Empirical evidence from the EU countries, Applied Economics Letters, 26 (2), 163-167 (2019)

7. Official website of the Government of Russia, The Russian Government (2015). Access mode: http://government.ru/info/19839

8. I. V. Terzi, Innovative activity of Russia in the index of global competitiveness, Scientific notes of the Tambov branch of RoSMU, 11 (2018)

9. The World Bank (2019). Access mode: https://www.worldbank.org

10. Analysis of state programs-2019 (2019). Access mode: https://ach.gov.ru/audit/gosprog$\underline{2019}$ 